\title{
Realization of high capacity transmission in fiber optic communication systems using Absolute Polar Duty Cycle Division Multiplexing (AP-DCDM) technique.
}

\begin{abstract}
An electrical multiplexing technique, namely Absolute Polar Duty Cycle Division Multiplexing (AP-DCDM) is reported for high-speed optical fiber communication systems. It is demonstrated that $40 \mathrm{~Gb} / \mathrm{s}(4 \times 10 \mathrm{~Gb} / \mathrm{s})$ AP-DCDM system shows a clear advantage over conventional $40 \mathrm{~Gb} / \mathrm{s}$ RZ-OOK with $50 \%$ duty cycle in terms of dispersion tolerance and spectral efficiency. At $40 \mathrm{~Gb} / \mathrm{s}$ its tolerance to chromatic dispersion (CD) is $124 \mathrm{ps} / \mathrm{nm}$ and $194 \mathrm{ps} / \mathrm{nm}$ for the worst and the best user, respectively. These values are higher than that of $40 \mathrm{~Gb} / \mathrm{s}$ RZ-OOK, which is around $100 \mathrm{ps} / \mathrm{nm}$. The spectral efficiency, receiver sensitivity and OSNR for different number of channels are discussed. Comparison against other modulation formats namely duobinary, Non-Return-to-Zero (NRZ)-OOK and RZ-Differential Quadrature Phase-Shift Keying (RZ-DQPSK) at $40 \mathrm{~Gb} / \mathrm{s}$ are made. It is shown that APDCDM has the best receiver sensitivity $(-32 \mathrm{dBm})$ and better CD tolerance $( \pm 200 \mathrm{ps} / \mathrm{nm})$ than NRZ-OOK and RZ-DQPSK. In reference to duobinary, AP-DCDM has better receiver sensitivity but worse dispersion tolerance.
\end{abstract}

Keyword: Chromatic dispersion; Duty cycle; Multiplexing; Optical communication. 